\title{
Pituitary Adenoma Apoplexy Presenting with Bilateral Third Nerve Palsy and Bilateral Proptosis: A Case Report
}

\author{
H. Ferhan Komurcu ${ }^{a}$ Giyas Ayberk $^{b}$ M. Faik Ozveren ${ }^{b}$ Omer Anlar $^{\mathrm{a}}$ \\ Sections of a Neurology and ${ }^{\mathrm{b}}$ Neurosurgery, Ataturk Training and Research Hospital, Ankara, Turkey
}

\section{Key Words}

Pituitary apoplexy • Third nerve palsy • Proptosis •

Pituitary adenoma

\begin{abstract}
Objective: To report a case of pituitary adenoma apoplexy presenting with bilateral proptosis and bilateral third nerve palsy that developed after cardiovascular surgery. Clinical Presentation and Intervention: A 45-year-old man developed bilateral proptosis and bilateral third nerve palsy after a coronary artery bypass grafting operation. A pituitary macroadenoma with extension into the sphenoid sinus and cavernous sinus with bilateral involvement was resected on computed tomography scan by microscopic transsphenoidal procedure. Third nerve palsy improved partially on the first postoperative day and completely improved in the fourth month after the operation. Conclusion: This is a rare case of pituitary adenoma apoplexy that presented with bilateral third cranial nerve palsy.
\end{abstract}

\section{Introduction}

Pituitary apoplexy after coronary artery bypass surgery is a rare and underdiagnosed complication with variable clinical presentations. The outcome may change because of early diagnosis and proper intervention [1]. Isolated third nerve palsy is rarely associated with pituitary adenomas; however it occurs most frequently due to a rapidly expanding posterior communicating artery aneurysm with impending rupture [2]. Extraocular palsy may be a sign of cavernous sinus invasion or extrinsic compression by pituitary tumors, suggestive of advanced disease. It develops in patients with established visual field defects and pituitary apoplexy and may be associated with other cranial nerve palsies, including nerves 3 , 4, 6 and less commonly nerve 5 [3]. Nearly all reported cases of isolated third nerve palsies in pituitary tumors are unilateral. We report here a rare case with pituitary adenoma apoplexy presenting with bilateral proptosis and bilateral complete third nerve palsy that developed after coronary artery bypass surgery.

This report was presented as a poster at the 19th World Congress of Neurology (WCN 2009) in Bangkok, Thailand during 24-30 October 2009 (abstract P017-TU-09).

Hatice Ferhan Komurcu, MD, PhD

Neurology Section, Ataturk Education and Research Hospital

Bilkent, TR-06800 Ankara (Turkey)

Tel. +905325944702

E-Mail skomurcu@ hotmail.com 


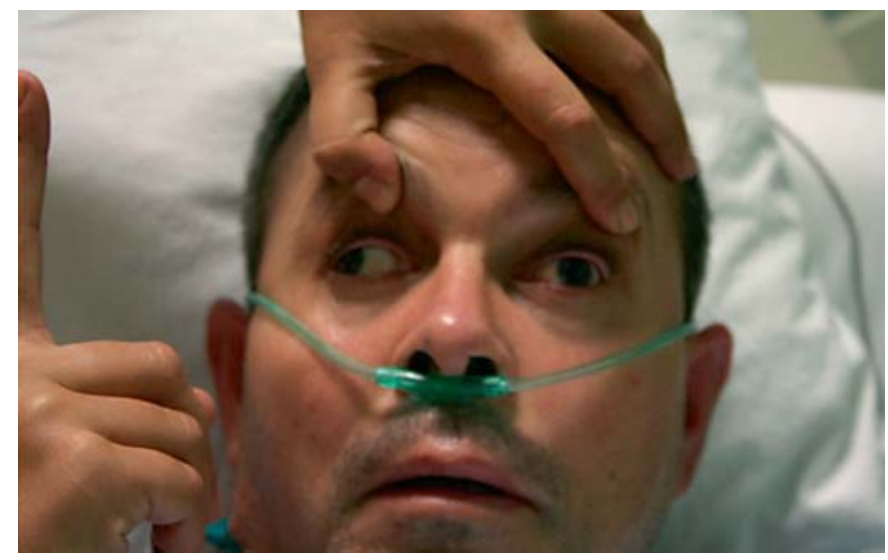

Fig. 1. Eye findings before resection of the pituitary adenoma.

\section{Case Report}

A 45-year-old man was admitted to the coronary care unit for acute inferior myocardial infarction and underwent a coronary artery bypass grafting operation by median sternotomy without any complication. Ptosis and midriasis in the left eye were seen $4 \mathrm{~h}$ after surgery. The next day he complained of a headache. Neurologic examination revealed bilateral midriasis, restriction in upward, downward and medial gaze in both eyes, bilateral proptosis and visual loss in the left eye (fig. 1). Although it was prominent in the left eye, both eyes were deviated laterally.

Because of the endotracheal tube after the cardiac surgery, magnetic resonance imaging was not performed, but an urgent head computed tomography (CT) was done. It showed a $36 \times$ $34 \mathrm{~mm}$ solid mass with a smooth contour resembling a macroadenoma in the pituitary fossa. The mass extended into the sella, invading the dorsum sella and pushing the bilateral cavernous sinuses and the cavernous segment of the carotid artery (grade IV-C according to modified Hardy classification). The mass was prominently compressing the optic chiasm and obliterating the suprasellar cistern. During surgery, it was observed that the macroadenoma had eroded the anterior wall of the sphenoid sinus and had invaded the sinus. Beige-colored adenoma tissue, partly hemorrhagic in appearance, was evacuated by ring curette totally by microscopic transsphenoidal procedure. Corticosteroid treatment was given to the patient before and after surgery.

Pathologic examination revealed cells with small-oval nuclei and wide eosinophilic cytoplasm and necrosis and hemorrhagic fields. There were oncocytic changes in the cells. In the histochemical studies, some cells were GH-positive, FSH-positive, prolactin-positive and ACTH-negative. With this pathologic picture, the diagnosis was pituitary null cell adenoma.

The patient had isochoric and dilated pupils and no direct or indirect light reflexes after the transsphenoidal adenoma resection. There was ptosis in the left eye, which was deviated laterally. Left third cranial nerve paralysis and diplopia were present. Right eye movements were normal in all directions. The third nerve palsy improved completely in the right and partially in the left eye

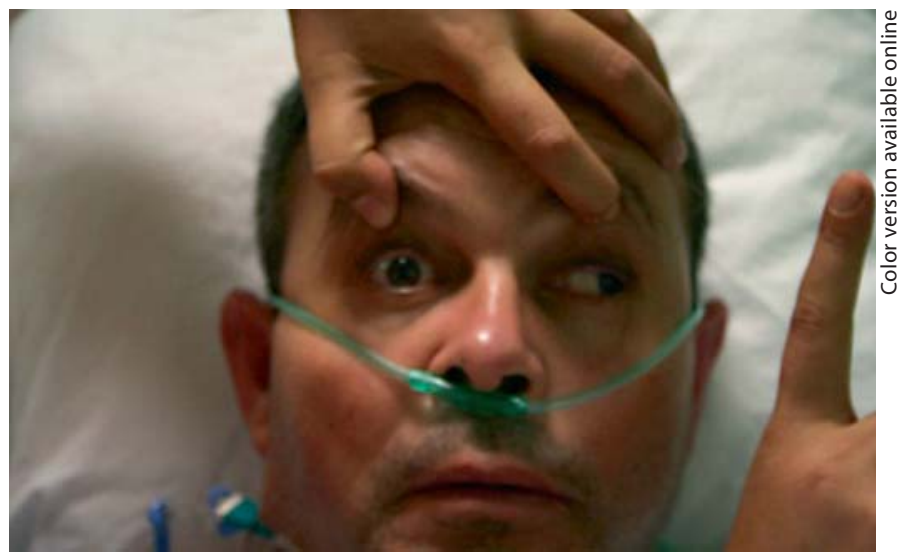

on the first postoperative day. The patient was discharged from the hospital with steroid maintenance. All ocular neurologic deficits improved completely in the fourth month of follow-up after the operation. CT examination in the sixth month showed enlargement in the sella, erosion in the dorsum sella, and a defective appearance at the sphenoid sinus wall and the sella floor due to surgery. No residue or recurrent tumor was present.

\section{Discussion}

Pituitary apoplexy is an acute life-threatening hemorrhage or infarction in the pituitary glands causing damage to the gland and surrounding sella structures due to the size of the tumor. Our patient had not complained of any symptoms related to the adenoma before surgery and therefore he is an example of an unexpected clinical course and neurological presentation with an occult pituitary adenoma. His neurological deficits developed just after coronary artery bypass grafting surgery.

Cardiac surgery presents several challenges to the circulatory and endocrine systems, including heparin administration, absence of pulsatile flow during cardiopulmonary bypass and microemboli entering the cerebral circulation, all challenges that may cause pituitary apoplexy. Fragile pituitary adenoma tissue is more susceptible to ischemic challenge during the perioperative period [4]. The infarcted tumor or pituitary tissue, in addition to intraoperative anticoagulation, maybe susceptible to subsequent hemorrhage. The pituitary gland is highly vascularized and pituitary adenoma is at risk of hemorrhage because of the abnormal sinusoidal, hyalen changes, fibrinoid necrosis and thin-walled nature of the tumor vasculature [5]. Hence the ischemic tumor or pitu- 
itary tissue may increase in volume and may compress the surrounding structures [1]. Bilateral ocular nerve palsy and pituitary apoplexy have been reported without cavernous sinus involvement [3]. However, our patient's apoplexy involved the cavernous sinus with bilateral expansion without any symptoms before cardiac bypass surgery.

The greatest long-term success in the treatment of pituitary apoplexy is achieved after aggressive management with transsphenoidal decompression, even in severe cases $[4,5]$. Surgery is generally well tolerated and is the preferred treatment alternative for prompt decompression, especially for sudden visual field disturbance, severe deterioration of acuity, or mental status change $[1$, 4]. The optimal timing of the surgery in patients with pituitary apoplexy is not yet definite. In a study on 31 patients who underwent surgery for pituitary apoplexy, significant recovery of the visual field and visual acuity was reported with early surgery performed within 8 days. However, neuroophthalmic recovery after delayed surgery has also been reported [6]. The probable reason for the complete recovery of neurologic deficits in our case may be due to early surgery after the patient became symptomatic.

Steroid replacement treatment is recommended after surgical resection of pituitary adenoma [4], hence our patient was on steroid maintenance. In addition, while the mechanism is unclear, delayed decreases in serum cortisol levels may be seen in patients undergoing heart surgery with cardiopulmonary bypass. The secretion of ACTH may decrease performing cardiopulmonary bypass [4], therefore pituitary hypofunction can occur. Because of this phenomenon, corticosteroid replacement treatment is recommended pre- and postoperatively [1, $4,7]$.

\section{Conclusion}

This is a rare case of pituitary adenoma apoplexy that presented with isolated bilateral third cranial nerve palsy, proptosis, and vision loss after coronary artery bypass surgery. A full recovery was achieved after transsphenoidal resection of the pituitary adenoma.

\section{References}

1 Chen Z, Murray AW, Quinlan JJ: Pituitary apoplexy presenting as unilateral third cranial nerve palsy after coronary artery bypass surgery. Anesth Analg 2004;98:46-48.

-2 Kwan ES, Laucella M, Hedges TR 3rd, Wolpert SM: A cliniconeuroradiologic approach to third cranial nerve palsies. AJNR Am J Neuroradiol 1987;8:459-468.
-3 Lau KK, Joshi SM, Ellamushi H, Afshar F: Isolated bilateral oculomotor nerve palsy in pituitary apoplexy: case report and review. Br J Neurosurg 2007;21:399-402.

$\checkmark 4$ Pliam MB, Cohen M, Cheng L, Spaenle M, Bronstein MH, Atkin TW: Pituitary adenomas complicating cardiac surgery: summary and review of 11 cases. J Card Surg 1995;10: 125-132.

$\checkmark 5$ Mattke AF, Vender JR, Anstadt MR: Pituitary apoplexy presenting as Addisonian crisis after coronary artery bypass grafting. Tex Heart Inst J 2002;29:193-199.
6 Randeva HS, Schoebel J, Byrne J, Esiri M, Adams CB, Wass JA: Classical pituitary apoplexy: clinical features, management and outcome. Clin Endocrinol (Oxf) 1999;51: 181-188.

7 Lasheen I, Doi SA, Al-Shoumer KA: Glucocorticoid replacement in panhypopituitarism complicated by myelinolysis. Med Princ Pract 2005;14:115-117. 